\title{
Reseña y aportes de la hermenéutica: miradas desde el constructivismo
}

\author{
Review and contributions of hermeneutics: \\ views from constructivism
}

Luis Cruz Villalobos ${ }^{1}$

Resumen

En el presente trabajo se hace un breve recorrido por la hermenéutica como disciplina dedicada a la interpretación, haciendo referencia a sus orígenes (filosóficos y teológicos), desarrollo e implicancias para las ciencias cognitivas y sociales, en particular, presentando algunas conexiones plausibles con la metateoría constructivista contemporánea y la poética.

Palabras clave: hermenéutica, constructivismo, circulo hermenéutico, si-mismo, Heidegger, Ricoeur, poética.

\begin{abstract}
This paper provides a brief journey through hermeneutics as a discipline devoted to interpretation, referring to its origins (philosophical and theological), development and implications for cognitive and social sciences, introducing some plausible connections with contemporary constructivist metatheory and poetics.
\end{abstract}

Key words: hermeneutics, constructivism, hermeneutic circle, self, Heidegger, Ricoeur, poetics.

1 Centro de Investigación de Resiliencia y Espiritualidad - CIRES. Santiago de Chile. E-mail: cires. chile@gmail.com 
Toda lectura de un texto, por más ligada que esté al quid, a "aquello en vista de lo cual" fue escrito, se hace siempre dentro de una comunidad, de una tradición o de una corriente de pensamiento viva, que desarrollan presupuestos y exigencias.

Paul Ricoeur (2008, p.9)

\section{Introducción}

Abordar la hermenéutica para comprender sus aportes y hacerla dialogar con el constructivismo, amerita un acercamiento participativo. A continuación se cita un texto de Aristóteles sobre la interpretación, presente al inicio de sus tratados sobre lógica (Organon). Se invita al lector de este artículo a dar lectura al párrafo siguiente, citado en una traducción literal del griego o también llamada de equivalencia formal:

Lo en el sonido son símbolos de las afecciones en el alma, y la escritura de lo en el sonido. Y, así como las letras no son las mismas para todos, tampoco los sonidos son los mismos. Ahora bien, aquello de lo que esas cosas son signos primordialmente, las afecciones del alma, las mismas para todos, y aquello de lo que éstas son semejanzas, las cosas, también las mismas (Aristóteles, 1988, p. $\left.2^{2}\right)$.

¿Qué problemas surgen en la lectura de este texto? ¿Qué quiere decir? ¿Cuál es su significado? ¿Cuál es nuestra apreciación respecto de lo que plantea? Si el texto fuese presentado en su versión en griego ¿qué problemas surgen? ¿Cuál sería su significado? ¿Para quién?

Veamos el mismo párrafo, ahora en una traducción de equivalencia dinámica:

Las palabras expresadas por la voz no son más que la imagen de las modificaciones del alma; y la escritura no es otra cosa que la imagen de las palabras que la voz expresa. Y así como la escritu-

2 Seguimos aquí la traducción del texto de Aristóteles que hace Miguel Candel Sanmartín (1988), sin las conexiones sintácticas que él añade. Se cita página de versión en línea (ver referencia). 
ra no es idéntica en todos los hombres, tampoco las lenguas son semejantes. Pero las modificaciones del alma, de las que son las palabras signos inmediatos, son idénticos para todos los hombres, lo mismo que las cosas, de que son una fiel representación estas modificaciones, son también las mismas para todos (Aristóteles, 1992, p. 53).

Mantenemos nuestras preguntas anteriores, pero ahora añadimos: ¿Afecta en algo la traducción? ¿Qué elementos hay que tener en cuenta para una interpretación correcta del autor? ¿Qué factores hay que considerar para comprender efectivamente lo que quería decir el autor? ¿Por qué dice lo que dice? ¿Qué perspectiva relativa a la intelección o cognición existe en Aristóteles en este texto? ¿Cuál es mi opinión al respecto?

Veamos ahora un texto escrito casi dos milenios y medio después del párrafo del filósofo. Unas palabras introductorias de un libro sobre las ciencias cognitivas y la experiencia humana escrito por Francisco Varela:

La mente despierta en un mundo. Nosotros no hemos diseñado nuestro mundo. Simplemente nos hemos hallado con él; hemos despertado tanto a nosotros mismos como al mundo que habitamos. Llegamos a reflexionar sobre ese mundo mientras crecemos y vivimos. Reflexionamos sobre un mundo que no está hecho, sino hallado, y sin embargo también es nuestra estructura la que nos capacita para reflexionar acerca de este mundo. Así en la reflexión nos encontramos en un círculo: estamos en un mundo que parece estar allí antes de que comience la reflexión, pero ese mundo no está separado de nosotros (Varela, Thompson \& Rosch, 2005, p. 27).

Seguimos preguntando: Varela, por su parte, ¿qué nos plantea? ¿Qué quiere decirnos? ¿A qué nos invita? ¿Qué opinión tenemos respecto a su planteamiento? ¿En qué se parece y distingue con el de Aristóteles? ¿Por qué? ¿Cuál es la intención en sus cursivas (para hallado y círculo)? Para comprender su pensamiento completo respecto al tema en cuestión ¿qué debo hacer y qué no?

La hermenéutica está presente en nuestro diario vivir, la búsqueda de significado, la interpretación de textos, señales, gestos, experiencias, en 
fin. La disciplina que se ha dedicado a estas preguntas se le ha llamado hermenéutica, y circularmente hemos querido introducir el tema con dos textos que hablan directa y/o indirectamente del proceso de interpretación, de la búsqueda de significado.

En el presente trabajo haremos un breve recorrido por esta disciplina, sus orígenes, desarrollo e implicancias para las ciencias cognitivas y sociales, en particular, haciendo algunas conexiones plausibles con la metateoría constructivista contemporánea.

\section{Antecedentes}

Antigüedad y Teología

La palabra hermenéutica se remonta a la figura del dios griego Hermes, hijo de Zeus y Maya. Tal como su versión romana, Mercurio, fue el dios del comercio y los navegantes, encargado principalmente de mediar entre los dioses o entre estos y los hombres. Como mensajero de Zeus, Hermes, también se encargaba de transmitir a los hombres los mensajes y órdenes divinas para que estas fueran claramente comprendidas y correctamente acatadas. A partir de esto es que, etimológicamente, podemos hablar de la hermenéutica (Hermes-techné), en su sentido primigenio, como el arte de Hermes, la técnica del que interpreta, intermedia, comunica, da a conocer (Cf. Delius, 2005).

El acto de interpretar y de buscar sentido y comprensión a la experiencia está presente, implícita y explícitamente, desde los registros históricos más remotos de la humanidad, particularmente en las culturas antiguas donde se observan las primeras manifestaciones de administración social del sentido, ya sea de los mitos, los oráculos o los textos sagrados (Mayos Solsona, 1991). Sin embargo, en una línea más sistemática y consistente como disciplina intelectiva, según Ricoeur (2008), al referirse al origen

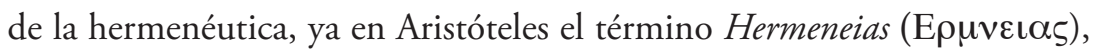
empleado en su Organon (Peri Hermeneias, ver cita inicial) atañe no solo a algunas modalidades particulares de contenidos (e.g. míticos, esotéricos), sino a todo discurso significante, e incluso más, ya que en sí mismo: 
el discurso significante es hermeneia, es decir, 'interpreta' la realidad, en la medida en que dice 'algo de algo'; hay una hermeneia porque la enunciación es una captura de lo real por medio de expresiones significantes, y no un extracto de supuestas impresiones provenientes de las cosas mismas (Ricoeur, 2008, p. 10).

A pesar de que la hermenéutica surge como disciplina, en la línea que hoy la comprendemos, en el contexto filosófico occidental, es en el ámbito teológico, particularmente de la exégesis, como interpretación de los textos sagrados de la tradición judeo-cristiana, donde adquiere un desarrollo notable, especialmente en el protestantismo ${ }^{3}$.

Las diversas perspectivas hermenéuticas en torno a la Biblia, desde un principio estuvieron definidas notoriamente por el status que se le asignaba al texto bíblico, es así que en los primeros siglos del cristianismo y, en especial, durante la Edad Media, las Escrituras tuvieron un lugar de preponderancia secundario, privilegiándose una hermenéutica de tipo alegórica o tipológica que pretendía captar la riqueza espiritual y moral de los textos en desmedro de su sentido histórico o gramatical $/$ literal $^{4}$. Sin embargo, no fue así en la Reforma protestante del siglo XVI, ya que en base al principio de Sola Scriptura 5 , el texto bíblico quedó como la máxima autoridad sobre la fe y la vida cristiana, desplazando al Magisterio (y toda autoridad eclesial y civil) a un lugar por debajo, incluso, de la libertad de conciencia y la libre interpretación de las Escrituras por parte de todo/a cristiano/a. Desde aquí surgen algunos de los primeros y más importantes avances disciplinarios en exégesis y hermenéutica, al iniciar el estudio detallado de los textos bíblicos en sus idiomas originales (hebreo y griego) e intentar una búsqueda rigurosa de interpretación histórica, gramatical y contextual ${ }^{6}$ de los contenidos de la Biblia, aunque esta resultara en el quiebre con la tradición y la interpretación imperante en el catolicismo romano (De Wit, 2001).

3 También encontramos importantes ejemplos de interpretación sistemática de textos en la tradición oral hebrea, que posteriormente se convirtió en el Talmud.

4 Prestándose para interpretaciones que no distinguían entre interpretar un texto alegórico de interpretar alegóricamente un texto que no tenían ese carácter literario.

5 Junto con los otros principios de Sola Gratia, Sola Fide y Soli Deo Gloria.

6 Es interesante considerar que las obras exegético-hermenéuticas de traducción de la Biblia realizadas por Lutero y Calvino, tuvieron una importante influencia en lo que fue el desarrollo moderno de la lengua alemana y francesa, respectivamente. 
Según De Wit (2001, p. 91), "el Renacimiento, el Humanismo y la Reforma establecen los cimientos de una nueva interpretación de la Biblia", cimientos desde los cuales, en los tiempos modernos, nace la investigación histórico-crítica, caracterizada básicamente por el hecho que los textos bíblicos serán examinados críticamente y se cuestionará, por ejemplo, la adecuación de la cosmovisión bíblica, implícita en ellos. “¡Los intérpretes perdieron la ingenuidad! En vez de ser reflejo confiable de la voz de Dios, el texto bíblico comienza a sentirse como complejo, problemático. Se comienza a cuestionar su confiabilidad" (De Wit, 2001, p. 94). Los métodos histórico-críticos, en términos generales, enfatizaron, por un lado, lo "metodológico", pues apuntaban a la utilización de métodos confiables para realizar un estudio científico de su objeto (los textos bíblicos), semejantes a las otras ciencias. Por otro lado, dieron gran relevancia a la "historicidad”, enfatizando la investigación específica del origen de los textos, sus fuentes, sus formas literarias, de redacción y de transmisión. Surgen, en esta línea, consecutivamente los distintos métodos históricos: crítica histórica (J. Wellhausen), crítica de las formas literarias (H. Gunkel), crítica de las tradiciones (G. von Rad y M. Noth), crítica de la redacción (Cf. De Wit, 2001).

En el siglo XX, aún en la perspectiva moderna, se observa el desarrollo de metodologías o perspectivas hermenéuticas que desde la sospecha leen los textos bíblicos como un conjunto de productos ideológicos, que pertenecen a un contexto y praxis social específicas. Entre estos enfoques encontramos las llamadas Lecturas Materialistas y Sociológicas, cuyo objetivo era romper con la dominación de la interpretación idealista, para que la Biblia fuese leída desde la lucha social de un modo militante, sin anhelo de objetividad o neutralidad. Metodológicamente privilegian el análisis histórico-sociológico del texto, en desmedro de la exploración de sus aspectos literarios y narrativos.

En la hermenéutica moderna también surge una teoría del texto con una serie de conceptos nuevos que intentan guiar la comprensión y la realización de una relectura. Dentro de los más importantes e influyentes representantes de este movimiento -que apunta a la apropiación del texto por parte del lector- están los filósofos (ambos de trasfondo protestante) 
H-G. Gadamer y P. Ricoeur. En estos autores la hermenéutica comienza a ser entendida como la teoría (o práctica teórica) que se ocupa de la pregunta ¿cómo es posible explicar y comprender textos históricos? Dado que se trata de comprender lo que está escrito por autores a los cuales ya no podemos entrevistar, Ricoeur plantea la metáfora del "diálogo" con los textos, ante lo cual podemos preguntarnos: ¿Qué debemos hacer para comprender lo que el otro dice? ¿Cómo será posible comprender el mundo de ese otro si nunca hemos estado allí? ¿Qué debemos hacer para no interrumpir al otro? ¿Qué debemos hacer para evitar que en ese diálogo estemos escuchando siempre el eco de nuestra propia voz? (De Wit, 2001).

Gadamer, por su parte, incorpora la connotación positiva en la distancia histórica entre el texto y el lector actual, pues para él el significado profundo de un texto va más allá de lo momentáneo y contingente, ya que un texto no dependería solamente del momento del autor histórico y su auditorio, sino que también la situación del lector actual sería constitutiva del mensaje, ya que comprender no sería nunca re-producir, pues siempre implicaría un proceso productivo (o constructivo), pues a través de la distancia histórica el sentido verdadero de un texto podría llegar a surgir, de tal modo que comprender un texto sería descubrir la pregunta que el texto quiere responder, la cuestión que el texto problematiza directa o indirectamente (Cf. Gadamer, 1993).

Ricoeur añade a la actitud existencial de Gadamer ante el texto, el uso de los resultados de la lingüística y la semiótica, logrando desarrollar un modelo hermenéutico muy interesante e integrador, que parte de la misma premisa de apropiación que Gadamer, planteando que el texto escapa al horizonte finito vivido por su propio autor, de tal modo que lo que el texto significa para el lector actual importa más que aquello que el autor quería decir consciente y deliberadamente cuando lo escribió. Es por ello que para Ricoeur el análisis del texto debe pasar por una actividad que él describe como "un arco hermenéutico" que va desde la comprensión ingenua inicial (existencial), pasando por la "explicación" (exégesis), para llegar al saber comprensivo (re-lectura) (Cf. Ricoeur, 2002).

La hermenéutica moderna, en el contexto bíblico-teológico, fue cambiando su foco desde la referencia del texto (realidad extratextual de 
origen), pasando por un interés en el texto mismo como objeto de estudio, para llegar a poner el énfasis en el lector y en su interacción significativa con el texto (ver Figura 1). En las hermenéuticas contemporáneas, partiendo de los últimos planteamientos de apropiación (Gadamer y Ricoeur), se inician variadas perspectivas de acercamiento al texto bíblico (desde la teoría literaria, el estructuralismo, la semiótica y la retórica), llegando a corrientes como la llamada Reader Response Criticism, que corresponde a una lectura posmoderna que enfatiza a el/la lector/a como coautor/a del texto; y las lecturas desde el deconstruccionismo, con su énfasis en la postergación del significado (e.g. Derrida, 1989, 2003).

Figura 1: Sistema Exegético-Hermenéutico y Tipos de Hermenéuticas

Sistema Exegético-Hermenéutico:

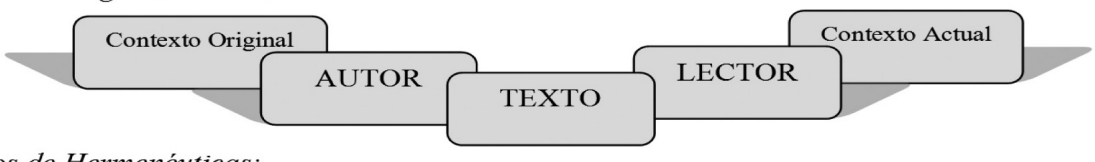

Tipos de Hermenéuticas:
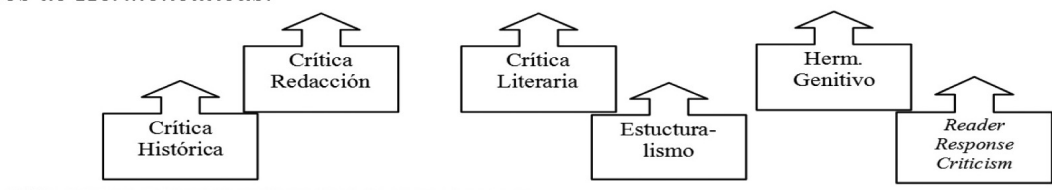

Fuente: elaboración propia.

\section{Hermenéutica y Filosofía}

Muy entrelazado con la práctica exegética y la teología (y con claras sobreposiciones de sus representantes, como veremos), el desarrollo de la hermenéutica en el ámbito filosófico se inicia para muchos con los aportes del teólogo y filósofo Friedrich Schleiermacher (1768-1834), en quien aparece como una disciplina o teoría general de la interpretación y la comprensión (Cf. Schleiermacher, 1998; Pfau, 1990; Mariña, 2005). La hermenéutica comienza a definirse como una disciplina concreta que intenta solucionar problemas prácticos y específicos dentro de una determinada disciplina (por ejemplo, en el campo jurídico). 
Aunque inicialmente la hermenéutica surge como una búsqueda del saber/interpretar correcto y sus respectivas reglas que permitan una compresión verdadera, dentro de su misma evolución como disciplina en el campo de la filosofía, ya con Wilhelm Dilthey (Cf. Dilthey, 1996; Tool, 2007) se presenta como una alternativa ${ }^{7}$ al objetivismo epistemológico, para quien toda comprensión auténtica en las ciencias que él llama "del espíritu" (para diferenciarlas de las ciencias de la naturaleza), pasaba por la detenida consideración de la cosmovisión ${ }^{8}$ propia de la época o cultura particular. La hermenéutica pone, desde Dilthey, el énfasis en que todo proceso comprensivo, especialmente los relativos al ser humano, se da a partir de un sujeto instalado en una relación de significación lingüística y habitando un contexto histórico específico (Mayos Solsona, 1991).

Es Martin Heidegger, tomando en parte los aportes de Dilthey y de la fenomenología de Husserl, quien consideró la hermenéutica no como un instrumento a disposición del hombre, sino como una estructura constitutiva del Dasein, concepto ya presente en Hegel y Jaspers, pero que Heidegger emplea de modo preponderante para referirse al ser humano en su condición de serlestar-ahí, como ser situado ineludiblemente de modo corporal, lingüístico, contextual e histórico (Cf. Heidegger, 1951). La comprensión hermenéutica es vista por este autor como una dimensión intrínseca del ser humano, ya que cada nueva experiencia nacería sobre el trasfondo de las experiencias procedentes previas y las reinterpretaría, siendo la hermenéutica, más que una forma particular del conocimiento, un modo de aproximación que hace posible cualquier forma de conocimiento, si se concibe la comprensión como una estructura de anticipación que muestra el carácter de lo "previo" (o pre-comprensión), de tal forma que

7 Aunque como bien indica Mayos Solsona (1991), ya en G. Vico (1668-1744) observamos una comprensión semejante a la que se plantea en la perspectiva hermenéutica moderna, pues en oposición a Descartes y su escisión radical entre sujeto (res cogitans) y objeto (res extensa), Vico plantea que ante tamańo abismo resulta imposible un conocimiento del mundo natural, pero no así de los ámbitos de las ciencias humanas, ya que el objeto del conocimiento no sería totalmente exterior, por tanto no existiría una distancia ontológica ni epistemológica entre sujeto y objeto, al menos en las ciencias que él llama históricas, espirituales o humanas.

8 Este término (Weltanschaunng) es acuñado por Dilthey, y se refiere a la visión de mundo, como un conjunto de saberes y referentes que conforman la imagen general del mundo que tiene una persona, época o cultura a partir del cual se interpreta la propia existencia y naturaleza como la del mundo en su totalidad. 
toda interpretación que implique una comprensión posterior tiene que haber comprendido ya lo que trata de interpretar. Es de esta concepción de donde surge lo que se ha llamado el Círculo Hermenéutico (que se abordará posteriormente).

Gadamer, discípulo de Heidegger, es reconocido como uno de los principales representantes de la filosofía hermenéutica. En su principal obra, Verdad y Método (1993), discute el alcance metodológico y filosófico de la hermenéutica, estableciendo una resistencia crítica a la pretensión de superioridad del método científico, pues para Gadamer este no es el único camino, ni menos el más adecuado, para explicar la experiencia del comprender, donde el lenguaje se presenta como el eficaz conductor que permite la experiencia interpretativa y la comprensión. De ahí que para este autor, la hermenéutica es planteada como una problemática general e inevitable, básica y universal de todo conocimiento humano, incluidas las ciencias naturales, pues es concebida como una teoría general de la interpretación, pero no poniendo el énfasis en la interpretación correcta, sino en qué significaría interpretar y comprender y cuáles serían las limitaciones y características fundamentales de este proceso (Cf. Gadamer, 1993; Mayos Solsona, 1991).

Gadamer plantea, en torno a la antigua discusión sobre sujetoobjeto, que ambos no corresponden a un modo de ser diferentes, sino que se co-pertenecen, son dos elementos inseparables en un mismo proceso cultural que los incluye por igual, pues para él el sujeto interpretador comprende desde los parámetros y límites que le ofrece su tradición cultural ${ }^{9}$ (la Weltanschauung de Dilthey), por ejemplo, respecto a la naturaleza de sí mismo y el objeto interpretado.

Si bien, los autores ligados al tema hermenéutico son variados en el campo de la filosofía, Paul Ricoeur (1913-2005), como ya mencionamos más atrás, es sin lugar a dudas uno de los que más ha aportado a la teoría hermenéutica, a tal punto que la filosofía para él es concebida en sí como hermenéutica, ya que entiende esta disciplina como un camino de lectura de las obras del hombre desde el lenguaje.

9 Además de su estructura y organización biológica, añadimos, tal como plantean ampliamente Maturana y Varela (2003). 
En el contexto actual, posmoderno, la hermenéutica ha tomado un lugar fundamental, de tal modo que se presenta como alternativa de acceso al conocimiento, reemplazando a la epistemología y la axiología, tal como observamos en las figuras 2 y 3 a continuación, donde se compara la Premodernidad, la Modernidad y la Posmodernidad desde la perspectiva de sus articulaciones filosóficas:

Figura 2: Premodernidad y Modernidad
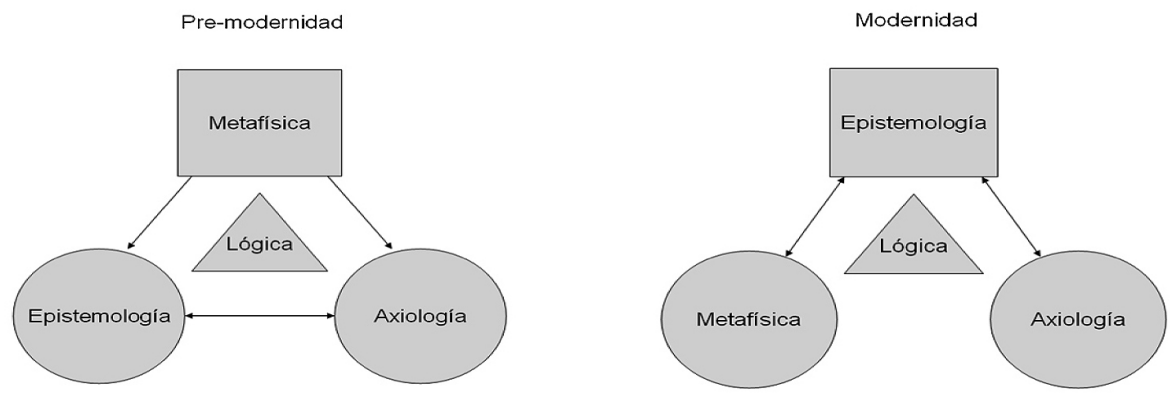

Fuente: Mitchell, 2009, pp. 145-146.

Figura 3: Posmodernidad
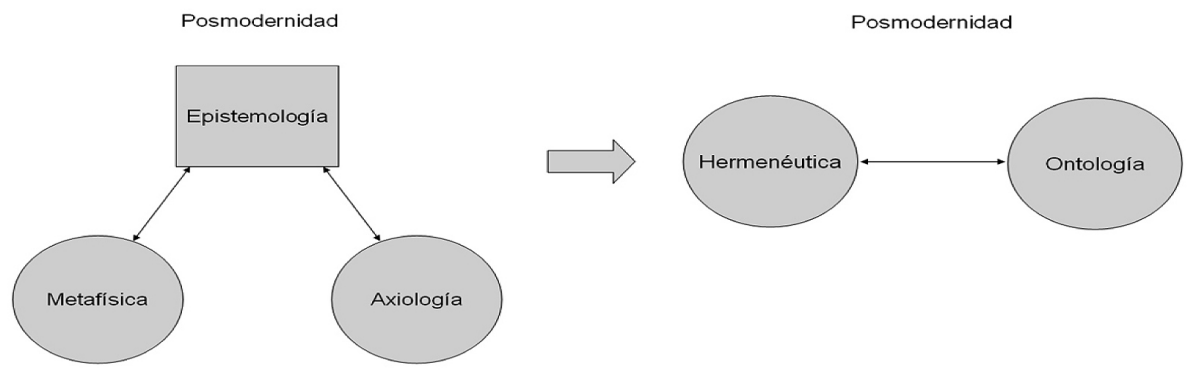

Fuente: Mitchell, 2009, p. 147. 
En la posmodernidad se reduce la epistemología y la axiología a la hermenéutica. Y, por otro lado, se reduce la metafísica (cosmología, teología, ontología) únicamente a la ontología. La lógica particularmente ya no jugaría un rol mediador, central ni preponderante.

Según algunos autores, como Rojas Osorio (2003), Nietzsche sería el que planteó la radical perspectiva, que impera en la posmodernidad, de que nuestras categorías filosóficas serían meras ficciones que fraguamos desde el lenguaje para metaforizar la realidad, de tal modo que solo contaríamos con metáforas y, por lo mismo, únicamente con interpretaciones, o más aún: con interpretaciones de interpretaciones, sin comienzo ni fin, sin que haya un primer referente desnudo de toda interpretación. La gramática nos jugaría pesadas bromas y nos haría creer que porque hay sustantivos hay sujetos. Las mismas categorías de la lógica, como el famoso principio de no contradicción, no serían sino ficciones útiles basadas siempre en axiomas indemostrables, como lo plateó Gödel (1981) con su teorema (Cf. Cruz Villalobos, 2010; Smith, 2007).

En palabras de Vattimo:

La metafísica, que empezó con la idea de que la verdad es objetividad, se concluye con el «descubrimiento» de que la objetividad es algo que el sujeto pone, y de que ese sujeto, a su vez, se convierte en un objeto manipulable. El efecto de todo ello es que la metafísica se refuta a sí misma precisamente cuando ella misma se cumple, al reducir todo el Ser a la objetividad. Desde ese momento, no podemos ya pensar en el Ser como en un objeto que se nos da ante los ojos de la razón -al menos porque, si así lo hiciésemos, habríamos de negar luego que nuestra propia existencia (hecha de proyectos, recuerdos, esperanzas y decisiones) sea «Ser» (puesto que no es nunca pura «objetividad»)- (2003, p. 24).

El orden objetivo del mundo se ha hecho trizas, bien porque la tradicional imagen realista del conocimiento (como si la mente fuese un espejo que refleja fielmente las cosas como son fuera) no ha resistido las críticas filosóficas, bien porque, sobre 
todo, de hecho la voluntad de poder se ha afirmado como la única esencia de la ciencia-técnica, por lo que el orden del mundo, si lo hay, es una producción del hombre, de su intelecto y de su praxis (1996, p. 36).

Pasemos ahora a hacer un breve recuento de algunos elementos y aportes importantes que nos entrega la hermenéutica en perspectiva contemporánea, y una discusión en particular en torno a la concepción del sí-mismo.

\section{Discusión}

Hemos realizado una revisión de los antecedentes históricos de la hermenéutica, con el fin de abrir esta disciplina particularmente en el campo psicológico, dado que su estudio ha estado más presente en la teología y filosofía. A continuación iniciaremos la discusión de algunos de sus elementos fundamentales y aportes, que aquí se consideran como dignos de atención para las ciencias que se dedican al estudio de la conducta y cognición humanas.

\section{Elementos y Aportes de la Hermenéutica}

\section{Lo lingüistico e histórico del ser.}

Especialmente desde Heidegger, la hermenéutica comenzó a aplicar su modelo interpretativo de los textos al ámbito ontológico. De este modo, la realidad es vista como un conjunto de textos, mitos, narraciones, creencias, instituciones y otros productos culturales heredados, que fundamentarían la construcción de lo que es el ser humano y su mundo.

Para Heidegger (2000) el lenguaje es la casa del ser, donde habita el humano. De ahí que el mundo con sus objetos y lo que en él acontece, incluida la persona como ser-en-el-mundo, no pueden considerarse como objetos externos que se encuentran frente a un sujeto independiente, sino como una realidad constitutiva como seres situados. 
A pesar de la relevancia que tiene el lenguaje en la configuración de la vivencia humana, resulta difícil asumir planteamientos como los siguientes:

La hermenéutica enfatiza la lingüisticidad inevitable y constitutiva de todo acto humano (también en especial de los intelectuales). El lenguaje no es tan solo el intermediario inevitable y esencial en todo proceso de conocimiento o de comunicación, sino que es el componente esencial de todo acto humano. No es una herramienta del pensamiento, sino su misma esencia o naturaleza, el sustrato mismo que lo hace posible. No hay, cuando hablamos de actos humanos, nada que no sea ya lenguaje (Mayos Solsona, 1991, p. 40).

Esta perspectiva resulta extrema y muy parcial, en especial si seguimos la conceptualización de lenguaje delimitada únicamente por lo discursivo, como lo hace el autor (Mayos Solsona, 1991, p. 45), alejándose de definiciones más complejas y amplias como las de Maturana y Varela, quienes lo definen como "coordinación de coordinaciones conductuales consensuales" (2003). Pero particularmente resulta una perspectiva incompatible con las recientes investigaciones relacionadas con los sistemas de neuronas espejo, que ratifican la inmediatez de muchos procesos motores, cognitivos e interpersonales, sin mediación del lenguaje ${ }^{10}$.

Por otro lado, la hermenéutica también ha enfatizado que el mundo no puede ser pensado como algo fijo o estático, sino como una permanente realidad dinámica, pues siempre se daría como proceso que se despliega en el tiempo y que es articulado o construido como historia, como legado o tradición que se transmite socialmente. Todo proceso comprensivo pasa, por tanto, por la toma de conciencia de la historicidad fundamen-

10 Una neurona espejo es una neurona que dispara tanto cuando un animal actúa como cuando el animal observa la misma acción realizada por otro. Por lo tanto, estas neuronas "reflejan" la conducta del otro, como si el observador fuese quien emite la conducta. Experimentos con imágenes cerebrales utilizando Resonancia Magnética Funcional (fMRI) han demostrado que la corteza frontal inferior y el lóbulo parietal superior se activan cuando la persona realiza una acción y también cuando la persona ve a otra persona que realiza una acción. Se ha definido que en estas zonas estaría el Sistema de Neuronas Espejo humano. Este sistema particular contribuiría relevantemente al funcionamiento cognitivo (e.g. en la predicción de conductas, la interpretación de intenciones) y motor, junto con estar involucrado con actitudes y comportamientos pro-sociales, por ejemplo, la empatía (Keysers \& Gazzola, 2010; Rizzolatti \& Craighero, 2004; Rizzolatti \& Fabbri-Destro, 2010). 
tal del ser humano y, por lo mismo, la asunción de que toda interpretación y comprensión surge y está situada en una determinada realidad histórica y procesal, por lo cual siempre será parcial, relativa y contingente.

En definitiva, la hermenéutica contemporánea, aporta a las ciencias sociales, en particular, la visión del ser humano como un ser ontológica y epistemológicamente contextual y lingüístico, de modo marcado (aunque no absoluto).

\section{La precomprensión y el círculo hermenéutico.}

El ser humano no es un espectador imparcial de los fenómenos que observa, por el contrario, cualquier conocimiento de las cosas viene mediado por una serie de prejuicios, expectativas y presupuestos recibidos desde la cultura imperante, que orientan y limitan selectivamente nuestra comprensión y autocomprensión, además de presentar condicionamientos estructurales y funcionales, particularmente a nivel de nuestra constitución como organismos vivos, poseedores de un sistema nervioso complejo. Por lo mismo, el hecho de que no solo los objetos de conocimiento estén situados históricamente, sino también que el hombre mismo lo esté, nos dificulta considerar la posibilidad de una valoración neutral, objetiva o directa de la realidad, como un mundo externo.

Tal como Heidegger lo decía (1951), el hombre está arrojado a un mundo, y en él se encuentra ineludiblemente acoplado a un cultura y con un lenguaje determinados que definen el qué y el cómo de su conocimiento de la realidad y de sí mismo. La implicancia de esto es que toda pregunta prevé su respuesta y presagia o anticipa aquello para lo que busca respuesta; siempre hay una hipótesis implícita o explícita con la que el que indaga se aproxima a su objeto de estudio, pues no se puede comprender lo que no tiene nada en común con uno mismo, y lo común siempre implica una precomprensión de lo que se trata de comprender o interpretar, de tal modo que no puede haber comprensión sin precomprensión previa, por lo cual se crea cierta circularidad en la comprensión, lo que se ha denominado círculo hermenéutico (Mayos Solsona, 1991). 
Heidegger concibe la circularidad hermenéutica de la comprensión como una oportunidad positiva más que como una limitación meramente restrictiva en el ser humano. El círculo hermenéutico viene a ser un límite a cualquier intento de comprensión totalitaria, pero también una liberación del conceptualismo abstracto "desencarnado".

Hay que entender el círculo hermenéutico como un argumento crítico que destruye toda pretensión de una interpretación neutra, absoluta e incuestionable. Al contrario, muestra que la naturaleza de la comprensión es de tal manera que no permite pensar en una realidad en sí o absolutamente determinable, en una VERDAD en mayúsculas o en un final en el proceso acumulativo y progresivo de desvelamiento de la "auténtica" comprensión. El círculo es, por tanto, un argumento que más que abocar al escepticismo -la mera consideración negativa-, apunta hacia la liberación de la sumisión a la presuposición de la Interpretación Definitiva, y permite captar en toda su compleja riqueza el problema de la comprensión y de la creación intelectual (Mayos Solsona, 1991, p. 31, mayúsculas del original).

Por ello, dado que el ser humano vive situado en el lenguaje y el tiempo, resulta complejo concebir un conocimiento absoluto, objetivo y sistemático del mundo, del cual él forma parte constitutiva. Por tanto, la pretensión de verdad, desde la hermenéutica, es radicalmente distinta a la de las ciencias positivistas, y está completamente en la línea de la metateoría constructivista, que comprende el conocimiento humano como una construcción activa de la realidad y no el reflejo unívoco de ella, y concibe la verdad solo como una aproximación parcial y transitoria, características que surgen de la co-pertenencia del sujeto-intérprete al ámbito del objeto-interpretable.

\section{Aportes de la Hermenéutica a la Comprensión del Si-mismo}

En el ámbito de la psicología ya se han hecho importantes conexiones entre la hermenéutica y el estudio del comportamiento y la cognición humanas, como es el caso de Packer (1985) quien desarrolla, como alternativa a los enfoques tanto racionalistas como empiristas, lo 
que él llama investigación hermenéutica. Esta buscaría, no las estructuras formales ni de las leyes causales, sino más bien elucidar y hacer explícita una comprensión práctica de las acciones humanas al proveer una interpretación de ellas por medio de un acercamiento históricamente situado, que apunta a entregar una perspectiva que se dirige a los intereses y preocupaciones actuales, más que a leyes eternas, ahistóricas, y estructuras formales.

Por nuestra parte, nos detendremos en uno de los posibles aportes que pueden desprenderse del estudio de la hermenéutica como disciplina sumamente atingente a la psicología, que es lo que hasta aquí hemos querido dejar manifiesto, y esbozaremos una propuesta que integra tanto elementos de la hermenéutica como del constructivismo en torno a la fundamental temática del sí-mismo, que nos plantea importantes desafíos.

\section{Mismidad, ipseidad e identidad narrativa.}

La vida consciente humana está caracterizada de modo central, como dijimos, por su temporalidad e historicidad. La experiencia sensorial y afectiva en el ser humano es mediada desde el inicio de la alfabetización por las narraciones o relatos respecto a nuestro pasado y lo que imaginamos que será nuestro futuro, en base a nuestras experiencias pasadas y las explicaciones que hemos dado de ellas.

Con qué contamos:

Con el instante presente

... y las narraciones sobre nuestro pasado o re-presentaciones (volver al presente)

... y las narraciones sobre nuestro futuro o pro(e)yecciones (lanzar hacia adelante)

Recordados e imaginados como construcciones socio-afectivas... pero en el instante presente (Cruz Villalobos, 2012, p. 10).

Todas las personas requerimos de lo narrativo, entendido como la articulación cronológica, causal y temática de la vivencia real o lo imaginado, pues es uno de los modos en los que podemos acceder y comunicar, en especial, lo afectivo, que constituye un ámbito central 
en el ser humano como organismo relacional. Se ha llegado incluso a considerar la narratividad como una de las dos formas de procesamiento de la información presentes en las personas (Bruner, 2001).

Giampiero Arciero (2006, 2009, 2010; Arciero \& Bondolfi, 2009) es uno de los principales investigadores que en la actualidad desarrolla un modelo que incorpora lo narrativo ${ }^{11}$, siguiendo muy de cerca a Ricoeur, desde su fenomenología hermenéutica, aplicándola a la teoría clínica y psicopatológica.

Arciero describe a la dialéctica fundamental del sí-mismo como la relación entre la experiencia actual e inmediata del sí-mismo (ipseidad) y la sedimentación cognitivamente mediada del sí-mismo (mismidad) que cambia lentamente con el paso de la vida; dialécticas que caracterizaría a la estructura ontológica del ser humano (ver Figura 4).

Figura 4: Dialéctica de la Mismidad y la Ipseidad

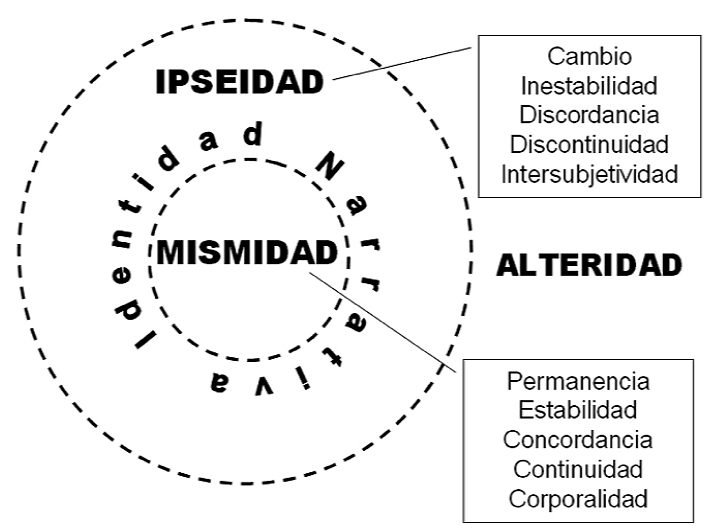

Fuente: elaboración propia.

Ricoeur (1996b, 2006) plantea al respecto el concepto de trama narrativa $^{12}$ que aplica de modo especial a la constitución de sí mismo, ya que para él la operación de la construcción de la trama narrativa puede

11 Aparte del amplio desarrollo que hizo, principalmente, M. White (e.g. 1993, 1997) respecto a la Terapia Narrativa, que aquí no abordaremos por alejarse del constructivismo y enmarcarse en una perspectiva básicamente post-estructuralista y más cercana al constructivismo social.

12 Tomándolo de la Poética de Aristóteles en cuanto al análisis que este hace de la tragedia griega. 
ser definida, en términos generales, como una síntesis de elementos heterogéneos: múltiples sucesos y factores, y la historia completa y singular, haciendo de la trama una totalidad que este autor denomina con el oxímoron de concordancia discordante o discordancia concordante, que en el plano de la identidad implica la integración narrativa (como identidad narrativa) de la polaridad de identidad como mismidad (asociada a la experiencia de permanencia, estabilidad, continuidad, particularmente corpórea) y de identidad como ipseidad (asociada a la experiencia de devenir, inestabilidad, discontinuidad, particularmente intersubjetiva).

En cuanto a la relevancia de lo narrativo, Arciero, nos plantea que en toda persona es permanente una "composición y recomposición de la identidad propia, como se evidencia en la configuración narrativa de los roles y los distintos personajes que pueblan el relato del Sí mismo" (Arciero, 2006, p. 71). En esta misma línea también expresa dicha relevancia indicando que:

La reconstrucción de los acontecimientos en la historia de una vida, mientras se integra el sentir y el actuar en una conexión narrativa (entrelazadas con experiencias posibles y con aquellas ya hechas) proporciona al protagonista de tales sucesos, la identidad y la estabilidad del Sí mismo en el tiempo. Siguiendo las huellas de Paul Ricoeur consideramos la construcción de la identidad personal como un proceso de interpretación, apropiación y reconfiguración de la experiencia pre-reflexiva (Arciero, 2010, pp. 7-8). Arciero también plantea que el lenguaje desempeña un rol clave para la apropiación del significado de la propia experiencia y la comunicación de sentido. La narrativa tendría el poder de reconfigurar en el ámbito lingüístico lo que ocurre en el ámbito del actuar y del sentir, componiendo y re-componiendo lo que ya es pre-reflexivamente manifiesto (Arciero, 2010).

\section{Lo narrativo y lo poético en dialéctica.}

Tal como nos indica Miró (2005), se ha observado que existen dos modos de organizar la experiencia, la forma oral y la forma escrita. La 
forma oral ha sido más propia en las culturas previas al desarrollo de la escritura, como a su vez en los niños preescolares, antes de su alfabetización.

En el mundo oral, como por ejemplo en la cultura griega antigua y en la tradición veterotestamentaria hebrea más remota, no existe un sentido diferenciado del sí-mismo (Havelock, 1982, en Miró, 2005). Es por ello que los registros parecen indicar que antiguamente se experimentaba el habla, los pensamientos, los sentimientos y las acciones como originadas fuera del yo, por ejemplo, en el habla de los dioses. Este es uno de los planteamientos que realiza Julian Jeynes (1987), quien formula la idea de que es muy probable que el hombre primitivo recurriera a la alucinación de una forma fisiológica como una manera de acceder a su mundo interno. En este sentido la alucinación podría haber sido una forma de mantener diálogos internos antes de que se desarrollara posteriormente la subjetividad, de este modo, la alucinación auditiva, por ejemplo, sería un equivalente a las cavilaciones que hoy mantenemos con nosotros mismos sin necesidad de alucinar, en la medida en que el raciocinio común es capaz de discriminar entre pensamiento y lenguaje. El hombre primitivo, inmerso en un mundo impredecible y amenazador, experimentaba lo cósmico y lo individual de un modo no fragmentado culturalmente, y sería la invención del alfabeto, como modalidad de comunicación que permite visualizar las palabras y distinguirlas de las ideas que estas expresan, la que habría dado origen a la idea de idea y a la noción de mente y sí-mismo, como depósito y agente de dichas ideas (Havelock, 1982, en Miró, 2005; Olson, 1994, en Miró, 2005).

Este modo de instalarse e interpretar la experiencia en el mundo podríamos conceptualizarlo poético, donde existe un predominio de la síntesis, la discontinuidad, la sincronía y la aprehensión intuitiva de la experiencia, que se distinguiría de lo narrativo, aunque esta distinción no es realizada por Ricoeur, Bruner, Guidano ni Arciero, al referirse a los aspectos narrativos de la experiencia humana. Lo narrativo se caracteriza, por su parte, por lo analítico, la continuidad, lo diacrónico y la aprehensión más sistemática de los contenidos en función de su causalidad y orden espacio-temporal. 
Desde esta perspectiva existirían dos modalidades hermenéuticas de situarse en el mundo, dos modos de experimentar e interpretar el ser situado: una más primitiva que llamaremos poética y otra filogenéticamente más reciente, que podemos llamar narrativa. De tal modo, que ante el excedente de significado medio ambiental (Varela, 1996) que demanda al ser humano una búsqueda de coherencia y regularidades que permitan la adaptación, esta puede ser encontrada por medio de dos modalidades de integración: una más asociada al sí-mismo como ipseidad, de carácter sintético, metafórico, sincrónico ${ }^{13}$ y sinérgico o bien, por medio de otra modalidad asociada al sí-mismo como mismidad, de carácter analítica, descriptiva, diacrónica y causal. Hasta ahora, los planteamientos de los autores que han abordado la temática narrativa respecto al sí-mismo, particularmente Ricoeur y Arciero a través del concepto de identidad narrativa, han omitido la distinción entre lo narrativo y lo poético, que a nuestro parecer es una veta de gran potencial investigativo, de tal forma que podemos hablar de identidad poética/narrativa, como modalidades hermenéuticas del si-mismo de predominio alternativo.

\section{Figura 5: Dialéctica Poética-Narrativa}

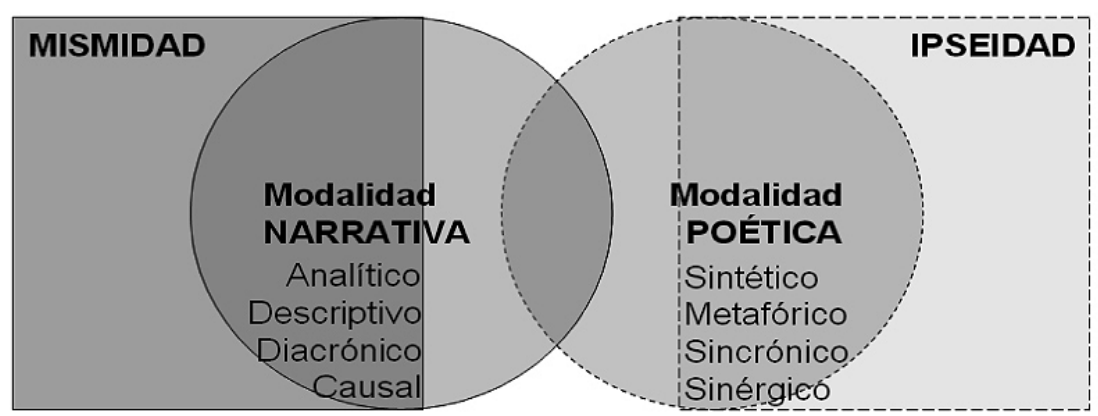

Fuente: elaboración propia.

13 Resulta relevante mencionar el reciente descubrimiento en la selva amazónica de una tribu que no tiene concepto para tiempo ni lo temporal: presente, pasado, ahora, mańana, ayer. (Palmer, 2011). Podría considerarse un ejemplo de una cultura situada predominantemente en modalidad poética, de acuerdo a lo que aquí estamos planteando. 


\section{Hacia una poética del si-mismo}

En consideración del olvido de la dimensión poética del símismo, por la patente focalización en las dimensiones narrativas, particularmente por su relevancia como organizadora de la experiencia en términos temporales, causales y temáticos, finalizaremos este trabajo refiriéndonos a algunos elementos de la hermenéutica del sí-mismo desde lo poético.

Si hacemos una conexión con la hermenéutica del arte, aplicada al campo psicológico, siguiendo a Gadamer, podemos adentrarnos en el estudio del proceso creativo como un ejemplo de espesor heurístico para dicha conexión.

Gadamer, refiriéndose a la experiencia del arte en general, nos dice en una de sus conferencias:

Si se considera que la tarea hermenéutica consiste en tender un puente que salve la distancia histórica o humana entre espíritu y espíritu, parece que la experiencia del arte cae fuera de su campo. ¿No es la experiencia del arte, entre todo lo que nos sale al encuentro en la naturaleza y en la historia, aquello que nos habla más inmediato y que respira una enigmática familiaridad que alcanza todo nuestro ser, como si no hubiese ninguna distancia entre ella y nosotros y todo encuentro con una obra de arte significara un encuentro con nosotros mismos? (1996, p. 2).

La obra de arte, que podemos llamar genéricamente "poema" (o poiema) y su proceso de ejecución como poiesis ${ }^{14}$, corresponde, según Gadamer, a la experiencia menos mediada en lo que respecta al acto hermenéutico, de interpretación, de tal modo que la construcción poiética nos hablaría de un modo particularmente directo acerca de nosotros mismos, al menos en algún sentido y/o ámbito.

14 Haciendo alusión a la distinción griega entre poieo ( $\pi \mathrm{o \iota \varepsilon o})$ y praxis $(\pi \rho \alpha \xi \iota \varsigma)$, siendo el primero el término referido al quehacer artístico, la manufactura creativa o artesanía, y el segundo, el que hace alusión a la acción en su sentido más ético (Cf. Pabón, 1967). Interesante, en relación a este párrafo, puede ser el concepto de auto-poiesis, desarrollado por Maturana y Varela $(1972,1980,2003)$ en el ámbito de la biología y la teoría del conocimiento, pero que en este trabajo no intentaremos conectar por ser un proyecto que demanda mayor espacio. 
Sin embargo, en todo proceso creativo, el autor tiene una experiencia mediada, desplazada, un diferir, pues el creador de una obra de arte, sea cual sea ${ }^{15}$, a pesar de ser el propio constructor, el "sujeto" del "objeto" creado que puede entenderse como proyección o reflejo de sí, establece una relación de alteridad con su obra (como con un "otro"), de tal modo que el reconocimiento personal en ella no es inmediato sino que se percibe como deformado, desplazado, diferido, particularmente por una significación posteriormente asignada, por lo cual, frente a la extrañeza inicial puede aparecer como acto segundo el reconocimiento.

$\mathrm{Si}$ "el arte no refleja lo visible, sino que hace ver" (Klee, 1956, en Harnisch, 1989, p. 9), podemos hablar de un círculo hermenéutico en el proceso de creación-observación de una obra por parte del mismo artista, quien solo después de un proceso de interpretación, similar al de cualquier observador/lector/auditor/a, logra reconocerse a sí mismo en la obra ${ }^{16}$, dado que:

las obras artísticas o culturales en general se caracterizan por haber dejado libres unos extremos del complejo significativo: referente, significado e interpretante (...) cualquier lector aporta el bagaje de su subjetividad llena de contenidos (...) Pues la obra a interpretar no es ya su producción (del autor) vinculada a sus motivaciones o presupuestos, sino aquella más allá de estos, desnuda, en sí misma o, mejor aún, abierta a ser completada en un acto interpretativo (...) la obra se caracteriza por la apertura a múltiples "planificaciones" o interpretaciones (Mayos Solsona, 1991, pp. 36-37).

Ahora bien, si realizamos un acercamiento al concepto de símismo, interpretándolo como una construcción artística (como poiema), desde el textualismo de Derrida (2003) donde los fenómenos son vistos como textos que adquieren una vida independiente del autor ${ }^{17}$ y una

15 Ya lo relacionaremos con la mayor obra humana que sería el si-mismo, comprendida como articulación narrativa, siguiendo a Ricoeur (1996b).

16 Obviamente, el autor mismo contará con información privilegiada, aunque siempre limitada dada la alta cantidad de procesamiento cognitivo inconsciente, que Freud abordó emblemáticamente y que las neurociencias siguen avalando (Cf. Gazzaniga, 1999).

17 En esto sigue la hermenéutica de apropiación que inician Gadamer y Ricoeur. 
polisemia dinámica, todo texto/fenómeno tendría la capacidad de ser lo mismo y lo otro, simultáneamente. A esto, Derrida (1989), le llama iterabilidad, entendida como la imposibilidad de bañarse dos veces en el mismo río, aunque conserve su nombre, tal como lo dijo Heráclito. De ahí que el significado no sería inherente al texto/fenómeno, sino que se encontraría más bien en la interacción entre el texto/fenómeno y el lector/ observador (Cf. Larraín, 2010).

Al aplicar esta perspectiva, y lo dicho con anterioridad sobre la interpretación en el arte, al constructo del sí-mismo, como una composición artística, podemos valorizar más profundamente la concepción de identidad narrativa que desarrolla Ricoeur, como una articulación entre el sujeto cartesiano (homuncular, sustancial, como sub-jetum o lo que subyace ontológica y gnoseológicamente) y el sujeto vaciado o ilusorio (presente en Hume, Nietzsche, también en Foucault y, en el campo de la neurociencia, notoriamente en Varela ${ }^{18}$ ), que concluye en una concepción narrativa del sí-mismo (Cf. Roldan, 2010), el cual brotaría en la interacción intersubjetiva y situada espacio-temporalmente, según el mismo Ricoeur en Tiempo y Narración (1995a, 1995b, 1996a), donde plantea que existiría un vínculo esencial entre la función narrativa y la experiencia humana del tiempo, de tal modo que el relato, o trama narrativa, será el medio privilegiado para esclarecer la experiencia temporal inherente a la condición humana de ser-en-el-mundo. Sin embargo, tal como mencionamos más arriba, esta inherencia de lo temporal solo sería parcial si aceptamos que existiría una modalidad de carácter sincrónico y sintético, que sería la modalidad poética, más primitiva en la experiencia humana, que integraría de un modo no temporal-causal-temático el sí-mismo sino como una experiencia sintética y sincrónica de carácter principalmente pre-reflexiva.

Para Ricouer el tiempo como realidad abstracta o cosmológica adquiriría significación antropológica en la medida que puede ser

18 Cf. Varela $(1996,2000)$ y Varela, Thompson \& Rosch (2005). Existe en Varela una notoria influencia por parte del budismo, la cual él explicita, particularmente en cuanto al concepto de yo virtual o yo vaciado de yo (anatta). Cf. Quiles (1973). 
articulado en una narración, pero esto sería solo una posible modalidad de articulación en el sí-mismo, de tal modo que el tiempo no solo se hace humano en cuanto se articula de modo narrativo.

La hermenéutica y sus desafíos abiertos

En el presente texto hemos querido presentar la hermenéutica como disciplina particular abierta al campo psicológico, reseñándola históricamente y compartiendo algunos de sus variados aportes para las ciencias en general y, particularmente, para las ciencias sociales o del comportamiento humano, pues el conocimiento de esta disciplina, al menos como un importante antecedente dentro de los desarrollos teóricos del constructivismo contemporáneo, es escaso.

Resulta evidente que el constructivismo epistemológico une sus raíces en los orígenes de la hermenéutica como antigua disciplina de la comprensión y la interpretación, por tanto, es importante valorar su camino y abrirse a sus más recientes planteamientos y a las plausibles integraciones y nuevos aportes en variados ámbitos del conocimiento.

Ricoeur nos dice que: "La metáfora es el proceso retórico por el que el discurso libera el poder que tienen ciertas ficciones de redescribir la realidad" (2001, p. 13), y es en ese "redescribir la realidad" donde está el poder que posee la palabra, especialmente, como narrativa diacrónica o como poética sincrónica en su devenir hermenéutico circular. Ahora, si esto lo aplicamos a la misma concepción del sí-mismo como articulación narrativa o como poeima auto-referencial, el potencial heurístico se multiplica y, aparte de surgir claras conexiones entre la hermenéutica como disciplina de la interpretación y las actuales aproximaciones epistemológicas que podemos incluir bajo el marco del constructivismo, también surgen elementos posibles para el desarrollo de una psicología hermenéutica que permita ampliar un diálogo multidisciplinario, que incorpore la filosofía, la literatura (poética) y las neurociencias, entre otras, que nos ayuden en la comprensión del hondo espesor de la experiencia humana. 


\section{Referencias}

Arciero, G. (2006). Estudio y Diálogos sobre la identidad personal: reflexiones sobre la experiencia humana. Buenos Aires: Amorrortu.

Arciero, G. (2009). Tras las huellas de Sí mismo. Buenos Aires: Amorrortu. Arciero, G. (2010). Vittorio Guidano a dieci anni Della scomparsa: reflessioni sul futuro del post-razionalismo. Entrevista Arciero-Liccione. Roma: IPRA. Recuperado el 25 de mayo de 2011 de www.ipra. it.22-mar-2010.

Arciero, G. \& Bondolfi, G. (2009). Selfood, Identity and Personality Styles. Oxford: Wiley-Blackwell.

Aristóteles (1988). Tratados de lógica (Organon). Madrid: Gredos. Recuperado el 10 de junio de 2009 de http://www.philosophia. cl/biblioteca/aristoteles/Arist $\%$ F3teles\%20-\%20Sobre\%20la\% 20interpretaci\%F3n.pdf

Aristóteles (1992). Tratados de lógica (El Organon). Bogotá: Ediciones Universales.

Bruner, J. (2001). Realidad mental y mundos posibles. Actos de la imaginación que dan sentido a la experiencia. Barcelona: Gedisa.

Cruz Villalobos, L. (2010). Teología, filosofía, ciencias: actuales caminos de humildad epistemológica. Correlatio, 9(18), 5-38.

Cruz Villalobos, L. (2012). Posibles deconstrucciones del trauma. Una aproximación posmoderna. Sociedad \& Equidad, 3, 172-194.

Delius, C. (Ed.) (2005). Historia de la Filosofia: desde la antigüedad hasta nuestros dias. Barcelona: Könemann.

Derrida, J. (1989). Márgenes de la Filosofía. Madrid: Cátedra.

Derrida, J. (2003). De la Gramatología. México: Siglo XXI.

De Wit, J. (2001). En la dispersión el texto es patria: introducción a la hermenéutica clásica, moderna y posmoderna. San José, Costa Rica: UBL.

Dilthey, W. (1996). Hermeneutics and the Study of History: Selected Works, Volume IV. Princeton, NJ: Princeton University Press.

Gadamer, H-G. (1993). Verdad y Método. Salamanca: Sígueme.

Gadamer, H-G. (1996). Estética y Hermenéutica, Daimon I, 12, 5-10.

Gazzaniga, M. (1999). El pasado de la mente. Santiago de Chile: Andrés Bello.

Gödel, K. (1981). Obras Completas. Madrid: Alianza Editorial.

Harnisch, W. (1989). Las parábolas de Jesús. Una introducción hermenéutica. Salamanca: Sígueme.

Heidegger, M. (1951). El Ser y el Tiempo. México: Fondo de Cultura Económica. 
Heidegger, M. (2000). Carta sobre el humanismo. Madrid: Alianza Editorial.

Jaynes, J. (1987). El origen de la conciencia en la ruptura de la mente bicameral. México, DF: Fondo de Cultura Económica.

Keysers, C. \& Gazzola, V. (2010). Social Neuroscience: Mirror Neurons recorded in Humans. Current Biology, 20(8), 353-354.

Larraín, J. (2010). El concepto de ideología. Vol. 4. Postestructuralismo, posmodernismo y posmarxismo. Santiago de Chile: LOM.

Mariña, J. (2005). The Cambridge Companion to Friedich Scheiermacher. Cambridge: Cambridge University Press.

Maturana, H. \& Varela, F. (1972). De Máquinas y Seres Vivos. Santiago de Chile: Editorial Universitaria.

Maturana, H. \& Varela, F. (1980). Autopoiesis and Cognition. The Realization of the Living. Dordrecht: Riedel Publishing Company.

Maturana, H. \& Varela, F. (2003). El árbol del conocimiento: las bases biológicas del entendimiento humano. Buenos Aires: Lumen.

Mayos Solsona, G. (1991). El abismo y el círculo hermenéutico. En G. Mayos Solsona, A. Penedo Picos \& J.L. Trullo-Herrera. Los sentidos de la hermenéutica (pp. 13-54). Barcelona: PPU.

Miró, M. (2005). La reconstrucción terapéutica de la trama narrativa. Monografías de Psiquiatría, 3, año 17, 8-18.

Mitchell, C. (2009). Cuadros sinópticos de filosofía y filosofos. Miami: Vida. Pabón, J.M. (1967). Diccionario Manual Griego-Español. Barcelona: VOX. Packer, M.J. (1985). Hermeneutic Inquiry in the Study of Human Conduct. American Psychologist, 40(10), 1081-1093.

Palmer, J. (2011). Amondawa tribe lacks abstract idea of time, study says. Science and technology reporter - BBC News. Recuperado el 25 de septiembre de 2011 de http://www.bbc.co.uk/news/science-environment-13452711

Pfau, T. (1990). Immediacy and the Text: Friedrich Schleiermacher's Theory of Style and Interpretation. Journal of the History of Ideas, 51(1), 51-73.

Quiles, I. (1973). Filosofía Budista. Buenos Aires: Ediciones Troquel.

Ricoeur, P. (1995a). Tiempo y narración, I, Configuración del tiempo en el relato histórico. México: Siglo XXI.

Ricoeur, P. (1995b). Tiempo y narración, II, Configuración del tiempo en el relato de ficción. México: Siglo XXI.

Ricoeur, P. (1996a). Tiempo y narración, III, El tiempo narrado. México: Siglo XXI.

Ricoeur, P. (1996b). Si mismo como otro. Madrid: Siglo XXI. 
Ricoeur, P. (2001). La Metáfora viva. Madrid: Trotta.

Ricoeur, P. (2002). Del texto a la acción. México, DF: Fondo de Cultura Económica.

Ricoeur, P. (2006). La vida: un relato en busca de narrador. Ágora-Papeles de Filosofía, 25(2), 9-22.

Ricoeur, P. (2008). El conflicto de las interpretaciones. Ensayos sobre hermenéutica. México, DF: Fondo de Cultura Económica.

Rizzolatti, G. \& Craighero, L. (2004). The mirror-neuron Sistem. Annual Review of Neuroscience, 27, 169-192.

Rizzolatti G. \& Fabbri-Destro, M. (2010). Mirror neurons: from discovery to autism. Exp Brain Res, 200 (3-4), 223-237.

Rojas Osorio, C. (2003). La filosofía en el debate posmoderno. San José, Costa Rica: EUNA.

Roldan, A. F. (2010). El sí mismo como otro. La alternativa de Paul Ricoeur entre el sujeto ensalzado y el sujeto humillado. En E. Assalone \& L. Misseri (Comps.). El giro subjetivista de la Filosofía Moderna. Perspectivas históricas y debates contemporáneos (pp. 461-468). Mar del Plata: Ediciones Cátedra de Filosofía Moderna.

Schleiermacher, F. (1998). Hermeneutic and Criticism. And other writing. Cambridge: Cambridge University Press.

Smith, P. (2007). An introduction to Gödel's theorems. Cambridge: Cambridge University Press.

Tool, A. (2007). Dilthey on the objectivity of knowledge in human sciences. Trames, $11(61 / 56), 1,3-14$.

Varela F. (1996). Ética y acción. Santiago de Chile: Dolmen.

Varela F. (2000). El fenómeno de la vida. Santiago de Chile: Dolmen.

Varela, F., Thompson, E. \& Rosch, E. (2005). De cuerpo presente. Las ciencias cognitivas y la experiencia humana. Barcelona: Gedisa.

Vattimo, G. (1996). Creer que se cree. Buenos Aires: Paidós.

Vattimo, G. (2003). Hermenéutica y experiencia religiosa después de la ontoteología. Revista de Filosofía Azafea, 5, 19-27.

White, M. (1993). Medios narrativos para fines terapéuticos. Buenos Aires: Paidós.

White, M. (1997). Narratives of therapist's lives. Adelaida: Dulwich Centre Publications.

Fecha de recepción: 08 de marzo de 2012.

Fecha de aceptación: 26 de abril de 2012. 